\title{
XXIX. Additional observations on hail, and on the organic bodies contained in Hailstones, \&c.
}

\section{Augustus Waller M.D.}

To cite this article: Augustus Waller M.D. (1847) XXIX. Additional observations on hail, and on the organic bodies contained in Hailstones, \&c. , Philosophical Magazine Series 3, 30:200, 159-171, DOI: $10.1080 / 14786444708645632$

To link to this article: http://dx.doi.org/10.1080/14786444708645632

曲 Published online: 30 Apr 2009.

Submit your article to this journal $\pi$

Џll Article views: 2

Q View related articles $\longleftarrow$ 
XXIX. Additional Observations on Hail, and on the Organic Bodies contained in Hailstones, \&c. By Augustus WaLLER, M.D.*

\section{[With a Plate.]}

I $N$ a preceding Number of this Journal (August 1846) I 1 have stated the results of a microscopic observation of hailstones previous to their fusion, and likewise of the water resulting from them. It was then found that this water contained particles of different shapes, which from their nucleated structure, globular form, and general appearance, were evidently of an organized nature. Since making these observations I have had an opportunity of repeating them, which occurred on the 1st of August, when London and the country in general were visited by that tremendous storm which has been the occasion of so much damage.

Aug.1.- - In my neighbourhood (Kensington) there occurred several falls of rain, which continued, with a few intervals, from about 4 P.M. to late in the evening: the fall of water was accompanied with frequent peals of thunder and flashes of lightning. With the drops of water particles of hail were occasionally found, which rarely reached the size of a bean. No damage was done to the hot-houses in this locality. One of these hailstones, perfectly white, when examined under the microscope in the ordinary way, presented the usual appearance of being composed of minute particles of ice, some spherical, others of a more irregular shape, and numerous bubbles of air escaped as it melted. The organized substances contained in the drop of water which resulted were numerous. Most of them were of an irregular shape with angular outlines. Others were globular; and some of these were completely black, with a nucleus in the centre. With higher magnifying powers were seen green globules about $\frac{1}{500}$ th of an inch in diameter, which were either collected in clusters or adherent together in single lines, like the beads of a rosary, as represented in fig. 1 of my former paper on hail.

In order to preserve the drop of water for a leisure examination free from dust in the atmosphere, I placed it in a little apparatus nearly air-tight, which will be described hereafter.

Aug. 2.- The drop of water thus secured and left under the microscope was found unaltered in size, but the organized matter had entirely altered its appearance. Some of the organized particles had given off filaments in various directions, as represented in Plate I.t, presenting the ap-

* Communicated by the Author.

+ The magnifying powers under which the objects are represented in this plate are as follows :-Fig. 1. magnified 360 diameters, fig. $\mathcal{2}$, 200 diameters, and fig. 3,300 diameters. 
Phit Hag: S. 3. To XXY. Flate 1

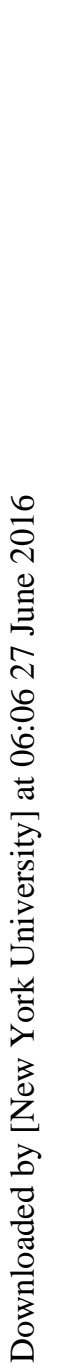
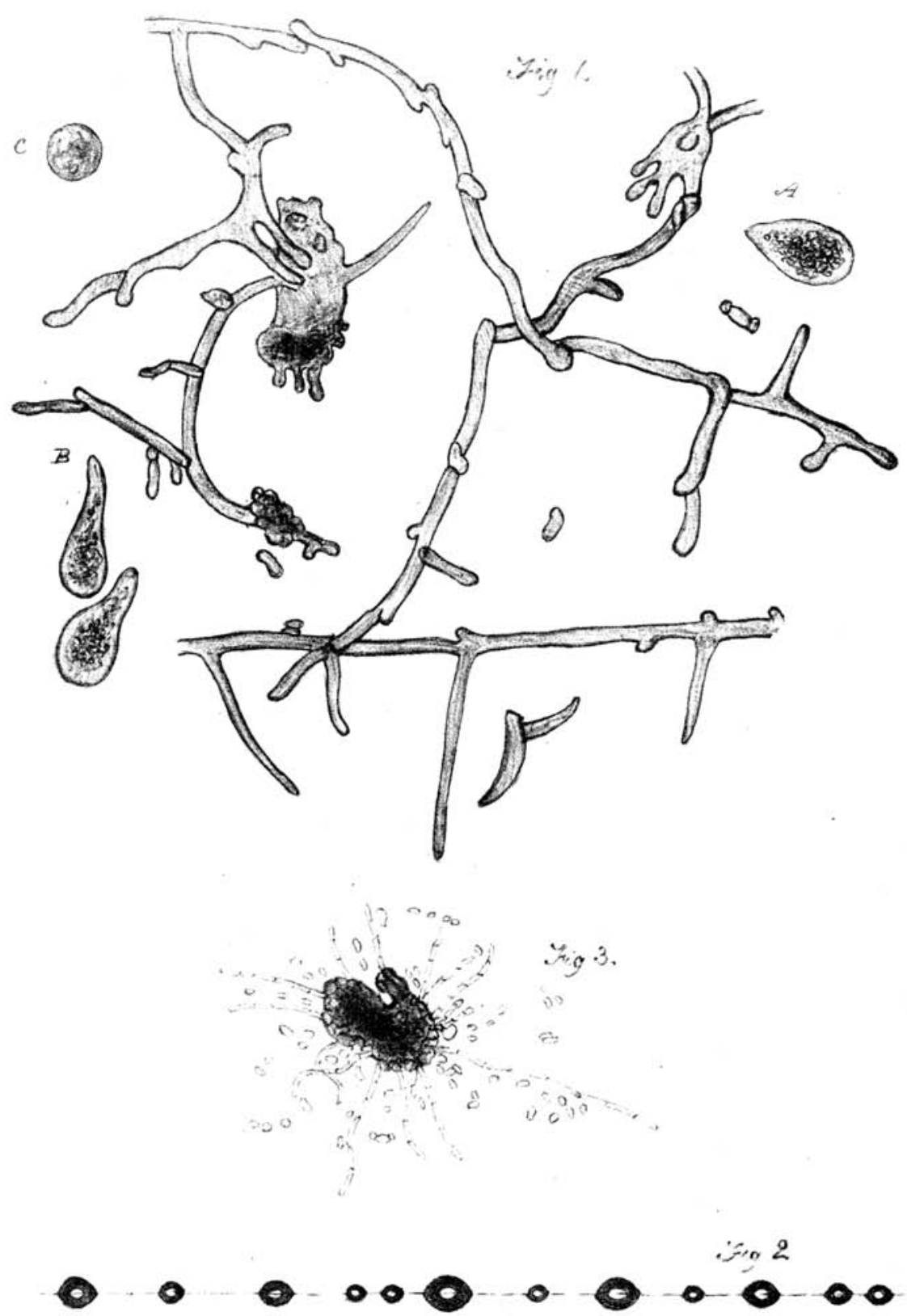

Organic Bodies contained in Haitstones. 
pearance of hollow tubes, jointed at intervals, with a few branches or subdivisions generally arising at the joints. The particles which gave rise to this vegetation appeared to me to belong to those which I have before described as the irregular angular particles. Among these one or two infusoria were likewise seen, moving about with great rapidity. When at rest their form was oval (A), but when in motion their anterior extremity frequently became elongated, as at $\mathrm{B}$. Their organization was extremely simple; no filaments nor appendages of any kind were to be detected about them. Their interior had a granulated appearance. All these characters indicate that they belong to the genus Uvella of the Monadinæ, and probably of the species Uvella glaucoma (Ebrenberg). $\mathbf{C}$ represents one perfectly circular, which was in a state of constant motion, revolving round its centre.

Aug. 3. - The vegetable filaments had greatly augmented in number. Small elongated cells, as represented, could be seen at various places, as if forming the first elements of the tubulous branches spread out around them. The infusoria had likewise greatly increased in number.

Aug. 4.- The same appearances were presented as the day before. Scarcely any alteration could be detected in the vegetable and animal bodies: the last were as active in their movements as before. I purposed to continue these observations every day, in order to ascertain their future changes; but unfortunately by some accident one of the slips of glass belonging to the apparatus was broken, and in consequence the water quickly dried up, so that when next examined the infusoria were found to be dead. The further addition of water was ineffectual to restore the vegetable particles to life.

For the purpose of repeating these observations, and likewise for many others of a microscopic nature, the little apparatus which I have made use of will be found very serviceable. It consists of a small square piece of sheet caoutchouc, more or less thick according as it may be required, with an aperture cut in the centre about the size of a shilling. On each side of it are placed two slips of glass of the same size, which, by a moderate degree of pressure, may generally be made to adhere to it so strongly as to render the little air-chamber, where the india-rubber has been cut away, perfectly secure from all access of dust and nearly air-tight. When the glass does not easily adhere to the caoutchouc, this last may be rendered sufficiently glutinous by heating it moderately. Instead of glass the plates may be of thin mica, which adheres still better; and from being so much more thin, will allow of the employment of the highest magnifying powers without the possibility of the access of foreign matter. I have sometimes 
used a metallic framework with a screw, by means of which the whole is rendered perfectly air-tight, and the glasses may be pressed nearly into immediate contact, but in most cases this is superfluous. As an instance of its efficiency in preventing all evaporation, I may state that I have preserved vaccine lymph in a fluid state in this manner during more than two months, with merely the assistance of a degree of pressure on the glasses, in the first instance secured by a few turns of wire. This is decidedly the most effectual mode of preserving this substance fit for use at any moment. A few of the same kind of apparatus in the pocket-book will be found most useful companions to the microscopic observer, when the slips of glass in ordinary use are inapplicable.

Although the existence of organized particles in the upper regions of the atmosphere appears at first very improbable, we shall find that several facts exist which much decrease this apparent improbability, and even some that appear to corroborate this statement. $M$. Boussingault has found that organic matter may invariably be detected in the atmosphere. It is true that his experiments have been confined to the loweratmospheric strata, and it would be very desirable to ascertain whether they hold good for those which are several thousand feet above the sea. The same may be detected in rain-water; and what is still more to the point, I find that M. Girardin (Académie des Sciences, April 1834) has detected in the water resulting from the fusion of hailstones, "a strongly azotized organic matter, and also lime and sulphuric acid without any trace of ammonia being present." The frequent vegetations in snow show at what a low temperature the vital principle may be sustained. The red and green appearance assumed by it has been found to be produced by the Hematococcus nivalis and the Protococcus viridis, as these plants have been termed, and which are probably the same species at different periods of growth, which have been found to penetrate many inches below the surface of the snow. These vegetations are found under the microscope to consist of minute globules, some green and transparent, about the size of $0^{\mathrm{mm} \cdot 01}$ to $0^{\mathrm{mm} \cdot 05}$; others red, generally larger than the former, and frequently arranged in single rows, like the beads of a necklace, adherent together. The globules are found of all intermediate tints between the green and the red, and likewise others of larger

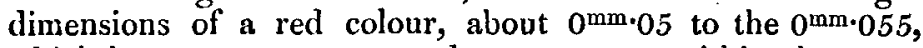
which have a more compound structure, as within them are seen several granules or smaller globules, which was not the case in the two former. M. Martens states, that in some of these globules microscopic infusoria may be detected (see 


\section{Dr. Waller's additional Observations on Hail,}

Kæmtz's Meteorology). I am not aware that the origin of this vegetation in snow has ever been satisfactorily accounted for; but when we consider how widely this vegetation is diffused, and the depth to which it penetrates, it does not appear unlikely that it may have fallen with the snow, in the same manner as the organic bodies in hail are brought fron the npper regions of the atmosphere. Further observations must determine how far these surmises are correct, and whether these bodies are not the same in both cases.

Again, in the hands of Ehrenberg the microscope has been the means of detecting, in dust fallen on ships in the Atlantic, the remains of above sixty different species of infusoria. Mr. Darwin, in his interesting paper in the Transactions of the Geological Society, mentions that dust has been collected in this manner at a pcint midway between Senegal and Cayenne. The distance to which volcanic ashes may be conveyed by the higher atmospheric currents, in a direction contrary to that of the lower prevailing winds, is well known. These facts being duly weighed, the frequent and even habitual existence of minute cryptogamic sporules and infusorian ovules in the higher regions of the atmosphere, where hail is formed, will not appear more incredible than the continued suspension of globules of water composing clouds; which globules, as neasured by diffraction, are found of far greater size than the former. The relation between the presence of these particles and other phænomena of meteorology remains to be determined, and how far they may be regarded as accompanying and detector agents of other atmospheric conditions following or preceding them; and whether the infusoria and the cryptogamia are the same at all seasons of the year; whether the locality in which they are collected has any influence; and lastly, whether they are the same in hail and water falling at about the same time.

In meteorology water likewise presents itself in what is termed the vesicular, as in clouds and fogs, in the condition of rain, snow and frost. In a paper which was read before the Royal Society, and which will appear in the Philosophical Transactions, 1847, will be found some experiments of mine upon water in the first-mentioned condition; with regard to the others I shall confine myself to the following remarks.

The transformation of fogs into rain is frequently taking place around us. Fogs, which at first are what is termed dry fogs, scarcely possessing the powet of moistening surrounding objects, after a time are found to deposit numerous small globules of water, which as long as they remain attached to minute filaments retain their spherical form, but when in con- 
tact with other bodies moisten them like common rain. This may be regarded as similar to the formation of rain in clouds, except that it is on a much smaller scale, as the thickness of the stratum of the fog is much less than the strata of clouds, as measured by M. Peytier.

We may examine the minute particles of rain or fogs, as I have already shown, by passing the air which contains them through essence of turpentine, lowered a few degrees below the common temperature. They are then left behind in the liquid; but at the same time they are mixed with others which arose from the condensation of the water contained in the air in an elastic condition. Difficulties exist with regard to the measurement of the globules while floating about. This is an objection to the employment of this method of fixing the globules. I have therefore endeavoured to use another means of observing these particles, and for this purpose have examined them as they exist on the filaments which compose the spider's web.

In order to examine these globules in situ, it will be found convenient to make use of two square frames of sheet cork of equal size, about two or three inches square. These are to be placed on each side of the web, then pressed together and bound. The whole of the web interposed may then be removed with the globules in statu quo, which may then be submitted to the microscope and measured. The globules may sometimes be as small as $\frac{1}{1500}$ th of an inch, which is less than the globules of the clouds in some instances as measured by Kæmtz. But generally these globules are much larger. They will be found placed at regular intervals, and while undisturbed show little tendency to coalesce; but when taken into a warm room they appear to lose with the increase of temperature, their cohesion to the line, and easily run off, coalesce with each other and rapidly evaporate; while so doing, instead of a globular form they become elongated ellipsoids, with the long diameter in the direction of the spider's line running through them. In the same fog I have found these globules always of the same dimensions. When the webs are examined over the extent of one or two miles at least, but in different fogs, their sizes are very different. It is necessary to wan the observer respecting an error that might be easily made in examining the web of the common spider, because in its natural state it is found covered with minute globules or beads, which contribute probably to secure the prey of the animal. These beads are arranged with great symmetry. Thus at nearly equal distances will be found globules, as in fig. 2, and between them others smaller dis- 


\section{Dr. Waller's additional Observations on Hail,}

posed with equal regularity. We may distinguish them readily, inasmuch as the globules of water soon disappear, whereas these beads are permanent, and unaffected by the vacuum of the air-pump. Mr. Blackwall has described them fully in the Transactions of the Linnæan Society.

Numerous particles of an organic nature may be detected in rain. But this investigation is liable to many errors which do not exist with regard to hail; because a solid body of ice will remain completely free from all foreign particles in the lower strata, and only contains those which were fixed within it at the moment of its solidification; while in rain we find a mixture of foreign bodies derived from various sources, which the drop of water meets on its passage from the point at which it is formed to the moment of reaching the ground, such as dust raised by the wind, pollen of flowers, and in the neighbourhood of towns, particles of soot continually floating in the atmosphere. It therefore requires great care to avoid coming to erroneous conclusions respecting the nature of the body under examination, and also to detect the existence of organic particles in the midst of others which mask its presence. For these reasons I avoid entering any further upon this subject at present, although deposits of rain-water have presented under the microscope several particles of an organic nature.

The most prevailing forms which the particles of snow in flakes assume, are minute acicular crystals irregularly grouped together, small regular rhombic prisms, often modified by secondary planes, and double six-sided pyramids, like the crystals of sulphate of potash. The more regular particles are generally found deposited on others more irregular, arranged in wreaths and various other shapes. A globular nucleus with small pyramids upon it is a frequent form in flakes of snow. Separate particles of snow affect much mure regular forms. In these the hexagonal form, or some tendency to assume it, is generally remarked; and examples of all the forms given in Scoresby's voyage, and of others still more complex, may be detected by the microscope in snow of this climate. The spongy deposit formed on the outside of vessels containing a freezing mixture is found under the microscope to present crystalline forms, which resemble the common forms found in snow much more than those of any other deposit, such as frost, or the arborescent deposit often found on the windows in winter.

In these experiments the hygrometric conditions of the atmosphere, the degree of refrigeration, and even the rapidity with which heat was abstracted, appeared to exert great influ- 
ence in modifying the crystalline forms that were obtained. In the same fall of snow a great uniformity is found in the forms of the separate crystals and of those which compose the flakes : sometimes there is only one prevailing shape, at others several very different distinct forms exist, falling at the same time. At the commencement of the fall the forms are generally more regular. In different falls of snow the forms of crystallization are scarcely ever alike or liable to be confounded; and even after a temporary cessation these are found to alter. In every respect we find the closest analogy between the formation of these crystals and those obtained from solutions in which the temperature, degree of condensation, and repose of the liquid, are found to have such influence. Some observations made on separate occasions will better elucidate these remarks.

Jan. 7, 1846.-There was a fall of snow, the flakes of which consisted of minute crystals of an octahedric form, placed on acicular ramifications of an irregular description. Besides these, small globules of ice studded with minute pyramidal crystals were perceived under the microscope. The snow examined at intervals was found to contain spherical globules without projecting crystals, which towards the end of the fall of snow gradually increased in size, and might be termed sleet, as they were visible to the naked eye: subsequently the sleet gave place to rain, consisting of minute drops. It is impossible to account for the formation of the mace-like particles of snow, without admitting, as in my experiments, two distinct periods or stages in their development. In the first stage the globular particle is deposited, and in the second the projecting pyramids are formed from moisture, condensed from either a gasiform or a liquid state.

Dec. $11,1846 .-$ A heavy fall of snow commencing early in the morning, which, after a temporary cessation at about 11 A.M., continued until 2 P.M. Many of the crystals were very regular, thin plates, which presented a hexagonal arrangement; some closely resembled fig. 15 of Scoresby's figures, as given in Kæmtz's Manual, without the projecting radii. Some were composed of a very thin hexagonal star, around which nearly circular apertures were disposed at regular intervals, and at the exterior of these six radii. The flakes were composed of irregularly-grouped particles; some of a lance-shape, size $\frac{1}{0} 0$ th of an inch; others regular six-sided prisms, like those of trost, about $\frac{1}{30} \frac{1}{0}$ th of an inch; and lastly, others nearly globular.

Dec. 12.-At about 10 A.M. there was a slight appearance of snow during nearly an hour. It consisted of separate par- 
ticles, which, from their size, form and colour, nearly resembled the eggs of the common blow-fly. At about 2 P.M. the snow fell more thickly, under the form of small conglomerations or balls, varying fiom the size of half a pea to three or four times larger. Pressed between the fingers, some of these pellets of snow were easily crushed; only a few offered any degree of resistance. To the naked eye they appeared to consist of spongy crystalline particles : under the microscope they were found to be composed of small regular crystals nearly cubical, mixed with others more irregular of complex outlines: the regular forms were exactly sinilar to the crystals of frost and the cube-like particles found in the snow on the day preceding. One of these balls submitted to the microscope on a slip of glass, began slowly to liquefy, from the contact of the glass and of the surrounding air. As this was taking place the liquid was diffused by capillarity over the entire mass, without any trace of moisture appearing externally until the entire ball was in a state of semi-fusion, and of a dull and semi-transparent white like a small hailstone: at the sume time the ball contracted in size and assumed a biconvex or lenticular shape. While these changes were taking place the crystals became fused at the angles and edges, most of them becoming globular and ovular: in this condition several of the balls were exposed to the open air, then several degrees below the freezing-point. When examined the next morning they were found perfectly hard, of a regular lenticular shape, of a dull white colour, in every respect like certain hailstones which I had collected during the summer. Under the microscope elliptic and circular particles were seen, like those composing hailstones. Previous to and during their fusion, bubbles of air were seen exactly as in the hailstones, though in less abundance. Some of these were enclosed, as represented at p. 105, vol. xxviii. Phil. Mag. This observation shows in a direct manner, with a much greater degree of precision than I conld have anticipated, the process of formation of hail as it takes place in general. In the first place, an agglomeration of crystalline particles, probably in consequence of certain vorticose currents, takes place in a globular shape. The ball of snow, thus formerl by the capillary attraction which it possesses from its porous structure, absorbs any moisture that may exist around it. 'The effect of this moisture is twofold ; first, as modifying the angular outlines of the component particles; and secondly, as binding them together into a consistent mass, which any further abstraction of caloric will reduce to the state of a hard and solid hailstone. If the addition of moisture is considerable, the liquefaction of the 
snow may continue until all traces of separate crystalline particles have disappeared and the air has been disengagel, the whole becomes transparent, and still capable, by its low temperature, of easily solidifying and forming a transparent mass of ice. In either case the deposition of successive layers of transparent ice, or of confused solit grains, may be accounted for by a continuance of the same actions.

In order to exemplify this, it is not requisite to confine ourselves merely to snow already in a globular state: any kind of snow slightly pressed into a globular shape becomes hardened and modified by diffusion of water through it, in consequence of slight melting of its particles. According as this is more or less continued, we obtain all the dull white tints of various hailstones. If the mass thus obtained be now exposed to the air below the freezing-point, the process is still further coinpleted by its entire solidification.

It still remained to be seen whether the conglomerations of snow contained, like hail, any organic particles. I was desirous to determine this point, because I considered them as being much less liable to contain foreign matter, such as dust \&c. of the lower strata of air, than the common flakes of snow: at the same time we must admit the possibility of the introduction of foreign particles, even after the entire formation of the ball, much more than in a solid body of ice like a hailstone,

In order to obtain a ball as free from impurity as possible, one of the hardest was selected, and after the exterior parts had been carefully brushed off, it was inclosed in the little apparatus before described. Several conglomerations were operated upon in this manner. In these the foreign particles were numerous; they all appeared irregular and of an amorphous inorganic nature, except some green globules closely agglomerated together, some in large quantities, others only consisting of groups of three or four: their size was about $\frac{1}{300} 0^{\text {th }}$ of an inch, and they were very similar to some found in hail, the vegetation of which was not examined (see p, 105, vol, xxviii. Phil. Mag.). The drops of water resulting, with their contents, were examined every day. The first two days they were kept in a room which averaged a few degrees above congelation; no alteration of the particles was detecterl. The third day they were exposed to the rays of the sun: on the fourth day the green globules had emitted slight filaments. Every succeeding day these filaments increased, and near them were transparent granules scattered about which increased very slowly, as represented at fig. 3. 'These vegetations were preserved for more than a month by occasion- 
ally adding a drop of distilled water, so as to prevent their complete desiccation. At the end of this time the group of vegetation had but slightly increased, but around were several other groups of vegetations of the same nature which were not perceived at the commencement of the examination. Their examination, which hitherto had been made nearly every day, was then abandoned as presenting no further object.

As it is possible to distinguish snow of different formations, its minute examination made simultaneously by different observers over a considerable extent of country, would enable us in all probability to determine several interesting points connected with the formation of snow. By their aid we might ascertain to what distance in certain cases the same crystalline form is preserved, and in what manner this is effected; whether by a simultaneous formation, or by a gradual propagation from one point to another; also at what rate of speed this is effected.

The frequent transformation of the vapours of water from the gasiform to the nebular state, commencing from a small cloud at the horizon and rapidly extending to the whole visible sky, bears a close analogy to the action of crystallization of bodies in solution in a liquid. In both cases a molecular action commencing from a circumscribed point is gradually propagated to the entire mass, when at a proper degree of saturation in the liquid solution the crystals formed are all alike. In the meteorological phænomenon, as it is a liquid that falls, the crystalline action cannot be observed; but the frequent production of hail renders it not unlikely that the clouds may sometimes be composed of solid particles.

From their connection with the preceding remarks I will mention the following experiments:-

Exp. 1. A saturated solution of sulphate of soda covered with a thin coating of oil was allowed to cool, and remained at rest for several hours. On a glass rod being brought in contact with the surface, the well-known phænomenon of the solidification of the solution ensued. The speed at which this solidification travelled from one extrensity of the tube to the other was at about the rate of one foot in forty seconds. The crystalline particles thus formed consisted of long aciculæ about $\frac{1}{1200}$ th of an inch in thickness.

Exp. 2. In a similar solution there were deposited, previous to its solidification, beautiful transparent, hard crystals, which are known to differ from Glauber's salts by their containing only eight equivalents of water of crystallization to one of salt. After the solidification had taken place the crystals were found to be changed to a milk-white colour, although they still retained the same shape. Under the microscope they were 
found to consist of minute irregular particles, which accounted for the change of colour and opacity. It appears, therefore, as if the molecular action, which causes the solidification, has the power of disaggregating or breaking up the crystalline arrangement of a body in a solid state.

Exp. 3. A solution of sulphate of soda which is not saturated, or has not been allowed to cool entirely, is affected by the contact of a foreign body much more slowly. After the lapse of several ninutes, the formation of separate clusters of crystals much larger than the former is observed: after about half an hour, these clusters were seen at numerous intermediate points throughout the length of the tube, which was several feet long.

Frost and snow examined under a magnifying power are much more alike than we should expect from their appearance to the naked eye. I have already mentioned the small, nearly cubical prisms, precisely like those of frost, which are found in snow. In the following instance of hoar-frost the likeness is still more complete.

Dec. 28, 1846.-The ground and all minute filaments were covered with abundant crystals of frost: thermometer $2 \tau^{\circ} \mathrm{F}$. The filaments of the spider's web were studded with quadrilateral prisins ranged transversely along the threads. In the afternoon a slight fall of snow occurred, whose particles were exactly like those of Dec. 12, except that they fell in large flakes. These were examined together with other particles of frost deposited on a web, and found to be precisely the same, except that the particles of snow were about a third smaller than those of frost.

Several salts manifest a peculiar tendency to ascend and crystallize on the sides of the vessel which contains them, but none of them so greatly as water when it solidifies in a cavity formed by moist earth. The first crystals formed are considerably above the surface of the water; and they increase until a solid crust is formed by them and the cavity below remains perfectly dry. Camphor, naphthaline, iodine and hydrosulphate of ammonia, resemble water in their volatile properties, and their tendency to solidify in a crystalline shape. The tendency of the first to deposit itself in crystals on the side of the glass nearest the light is well-known. Naphthaline in the same condition slowly deposits a few minute crystals on the same side : after the lapse of a month a few scattered clusters of them were formed, after which no further increase of them was perceived even at the end of several months. Iodine exposed in a large bottle to the sun during the summer formed deposits of different forms on various occasions, but all composed of rhombic Phil. Mag. S.3. Vol. 30. No. 200. March 184.7. 
plates slightly modified. Some of these rhombic crystals were separate, about the tenth of an inch in size, and with angles of about $50^{\circ}$ and $130^{\circ}$ : some of the crystals formed long, thin, narrow blades, above half an inch in length, with a bright metallic lustre: on their edges were two or three indentations indicating the separate crystals.

Hydrosulphate of ammonia.-This is to be oblained by bringing into contact ammonia and sulphuretted hydrogen in a gaseous state and perfectly dry at a low temperature. We then observe the formation of a white crystalline deposit on the sides of the vessel in which the gases are received. Any further directions respecting the mode of obtaining it will be found in Thenard's Chemistry, Berzelius, \&c.

Hydrosulphate of ammonia is so extremely volatile, that a piece of lint wetted with rether and placed in contact with any part of the bottle which contains it, causes the salt to form a deposit at the inner surface beneath. The crystals in these cases are frequently very regular hexagonal stars, like those of snow. A current of water falling on any part of the bottle rapidly produces the same effect. In summer it generally sublines to the upper part of the bottle, on account of the greater heat which is communicated to the base of the bottle by contact with the shelf on which it is placed. In a clear night the opposite effect is produced when placed in contact with the ground. But it is particularly when employed as a differential thermoscope that the indications of this salt are interesting. Thus, during a clear night the salt rapidly accumulates towards the points at which the greatest radiation of caloric takes place. $A$ bottle containing this salt placed between two unequal radiating surfaces, indicates, by its change of position, the difference in the radiation of these surfaces. In fact wherever the equable distribution of caloric is disturbed in the same direction for some time, the altered position of the hydrosulphate serves as an indicator of the course it has taken, and the forms of the crystals show to a certain extent the rapidity with which it has been effected, because where the action is rapid the crystals are much sinaller and more confused, than when it has been more gradual. It is surprising how small a difference in the radiating power is sufficient to alter the position of the salt when properly disposed. I will not at present enlarge any further on the thermoscopic properties of the hydrosulphate. It presents all the conditions corresponding to those of water. During its preparation it is frequently observed in the air in a state of microscopic crystals representing snow : the crystals formed by rapid evaporation are exactly like the hexagonal plates of snow. A more gentle action gives 
rise to crystallization, like those of frost and of congealed water. Although we have rarely seen it in a liquid state, yet during summer, under the influence of the sun's rays, its crystals become perfectly liquid and assume a globular form, and which they retain as they again solidify; forming, in these cases, conditions corresponding to water in a liquid state, ice and sleet.

XXX. On a Machine for Calculating the Products, Quatients, Logarithms, and Powers of Numbers. By the Rev. HeNRY Moseley, M.A., F.R.S., one of Her Majesty's Inspectors of Schools, and lately Professor of Natural Philosophy and Astronomy in King's College, London*.

[With a Plate.]

T HAVE proposed to myself in the construction of this 1 machine, to determine mechanically the products, quotients, logarithms, squares, square routs, and other powers and roots of the natural numbers, by means of combinations of greater simplicity than have hitherto been applied to the purposes of mechanical calculation.

The accompanying Plate II. is intended to illustrate the principle of the machine, but it does not show the mechanical details of its construction or the due proportion of its parts.

It will be observed that it consists principally of a cone and a screw. The application of the cone and the disc to various purposes of mechanical calculation has long been well known, and particularly by the ingenious applications made of the disc to dynamical admeasurement by MM. Poncelet and Morin.

The novelty of this instrument consists in the combination of the screw with the cone.

CD represents a small screw terminated by solid cylindrical axes or gudgeons, of which that shown by the letter $D$ is pro= longed, and carries an index $T$. The screw admits of being fixed in its bearings or made to revolve in them.

$P Q$ is a wheel having a hollow cylindrical axis, into which is accurately fitted a hollow cylindrical piece, whose internal surface is traversed by the thread of a female screw working upon the male screw $\mathrm{CD}$.

The hollow axis of the wheel PQ admits of being fixed upon the cylindrical piece inserted in it, or of being disengaged from that piece, so that the wheel $P Q$ may be made to carry the female screw round with it in its revolutions, or to turn freely upon the outside of the cylinder which contains that screw, as upon an axis.

* Communicated by the Author.

$\mathrm{N} 2$ 